\title{
Gut-Brain Communication is Influenced by Gut Microbes
}

\author{
Vatsala Dwivedi $\cdot$ Rup Lal
}

(C) Association of Microbiologists of India 2011

Mammalian brain is of particular interest to us and is susceptible to environmental influences during perinatal life. A recent study by a group of researchers at Stockholm Brain Institute and Genome Institute of Singapore revealed that the gut bacteria influence brain development and behaviour [1]. In their experiment they used two groups of mice and subjected them to similar conditions and recorded their variations in brain development and behaviour. One group of mice was raised with normal microorganism and referred as SPF (Specific Pathogen Free) and the other was devoid of it and hence referred as GF (Germ Free). It was observed that the GF mice were engaged in riskier behaviour than SPF. The GF mice had increased motor activity and reduced anxiety as compared to SPF. The changes in the behaviour of GF and SPF mice were attributed to gut bacteria. However, if the GF mice were conventionalized i.e. introduced with gut micro-bacterium in early development phase it exhibited the behaviour similar to the SPF one. The conventionalization of adult mice failed to restore the behaviour of GF mice.

The data supports the notion that in early life gut microbiota affect brain development and behaviour. However the mode and mechanism through which the gut bacteria change the development and behaviour of the brain is yet to be investigated. This study can be related to have wider implications in psychiatric disorders in humans.

\section{Reference}

1. Heitz RD, Wang S, Anuar F, Qian Y, Bjorkholm B, Samuelsson A, Hibberd ML, Forssberg H, Pettersson S (2011) Normal gut microbiota modulates brain development and behaviour. PNAS. doi:10.1073/pnas.1010529108
V. Dwivedi $(\bowtie) \cdot$ R. Lal

Department of Zoology, University of Delhi,

Delhi 110007, India

e-mail: dwivedivatsala@gmail.com

R. Lal

e-mail: ruplal@gmail.com 